\title{
The Deflationary Theory of Ontological Dependence
}

\author{
By David Mark Kovacs
}

(this is a draft; please cite the version forthcoming in Philosophical Quarterly!)

\begin{abstract}
When an entity ontologically depends on another entity, the former "presupposes" or "requires" the latter in some metaphysical sense. This paper defends a novel view, Dependence Deflationism, according to which ontological dependence is what I call an aggregative cluster concept: a concept which can be understood, but not fully analyzed, as a "weighted total" of constructive (roughly: mereological in the broadest possible sense) and modal relations. The view has several benefits: it accounts for clear cases of ontological dependence as well as the source of disagreement in controversial ones; it gives a nice story about the evidential relevance of modal, mereological and set-theoretic facts to ontological dependence; and it makes sense of debates over the relation's formal properties. One important upshot of the deflationary account is that questions of ontological dependence are generally less deep and less interesting than usually thought.
\end{abstract}

Keywords: cluster concepts, deflationary ontology, determination, grounding, ontological dependence, symmetric dependence

\section{Introduction}

When some $x$ ontologically depends on some $y, x$ in some metaphysical sense "requires" or "presupposes" $y$ : sets are thought to depend on their members, wholes on their parts, structured facts on their constituents, tropes on their bearers, holes on their hosts, and so on. Ontological independence has traditionally been regarded as a criterion of metaphysical self-sufficiency, and for this reason sometimes also of substancehood. Recent years witnessed a surging interest in ontological dependence. ${ }^{1}$

I should flag at the outset that 'dependence' has also been used in a broader sense in metaphysics. Functional realisation, micro-basing, and most recently grounding, are sometimes described as "dependence relations", though it would be

${ }^{1}$ See, e.g., Simons (1982), Mulligan, Simons \& Smith (1984), Fine (1995), Correia (2005), and Koslicki (2012). 
more accurate to call these determination relations. ${ }^{2}$ If ontological dependence is a kind of presupposition, determinative notions are linked to a kind of metaphysical explanation. Although dependence and determination have something in common (they both impose a kind of non-causal priority), it's a mistake to automatically assume that $x$ determines $y$ iff $y$ ontologically depends on $x$. To begin with, there are plausible counterexamples to both sides of this biconditional. Against the "only if" part: disjunctive facts are widely thought to be grounded (and so determined) by their true disjuncts, but they don't always depend on this disjunct. For example, $\mathrm{Pv}_{\mathrm{v}} \sim \mathrm{P}$ may be determined by contingent fact $\mathrm{P}$ but doesn't depend on it; the disjunction is a logical truth and doesn't "need" or "presuppose" such contingent facts in any way. Against the "if" part: suppose facts ontologically depend on their constituent individuals and properties (cf. section 5). Take an arbitrary fundamental fact, e.g. that a certain electron has negative charge. This fact may ontologically depend on its constituents, but since it's a fundamental fact, it lacks a metaphysical explanation and so isn't determined by anything (given a widespread definition of fundamentality). ${ }^{3}$

The aforementioned cases are resistible, as counterexamples usually are. But there is also a general reason why dependence isn't the converse of determination. Ontological dependence involves a (perhaps, but not obviously, modal) constraining of the prior thing by the posterior thing. By contrast, determination relations involve

2 See Melnyk (2003: Ch. 1), Kim (1998: 80-7), and Bliss and Trogdon (2014), respectively, for introductions to these relations.

3 See also Schnieder (forthcoming: \$4.6) for further counterexamples to a similar equivalence thesis (he uses slightly different terminology). 
a similar constraining of the posterior thing by the prior thing. This constraining runs in opposite directions in the two cases, and we shouldn't simply assume that they systematically coincide.

Perhaps there is some subtler connection between grounding and ontological dependence ${ }^{4}$; here I just warn against their straightforward conflation. In the present work, I will exclusively focus on ontological dependence: the kind of metaphysical presupposition/constraining that can be traced back at least to Aristotle and was later revived by Husserl - not grounding, not non-causal explanation, and not “dependence relations".

Until recently, most philosophers offered analyses of ontological dependence in terms that were usually thought better understood than the idioms of dependence (in what follows: a conservative analysis). For example, taking inspiration from Husserl, Simons (1982) developed a modal-mereological account of ontological dependence. More recently, Brian Ellis proposed a supervenience-based definition (2001: 82-3). However, by far the most well-known such account has been the

(Modal Analysis): For any $x$ and $y, x$ ontologically depends on $y$ iff, necessarily, if $x$ exists then $y$ exists. ${ }^{5}$

Unfortunately, the Modal Analysis is subject to counterexamples. For instance, as Fine (1995: 271) has pointed out, it implies that Socrates ontologically depends on

4 See Correia (2005: 66), Tahko and Lowe (2015: \$5), Jansson (2017: 34-9), and Schnieder (forthcoming: $₫ 3, \S 5.1$ )

${ }^{5}$ Moravcsik (1965: 107), Tlumak (1983), Hoffman and Rosenkrantz (1994: 95-6), Simons (1998: 236) 
his singleton set, and that everything ontologically depends on any necessary existent (e.g. Socrates on the number five). ${ }^{6}$ Most philosophers find these consequences unacceptable, and as a result either accept ontological dependence as an indispensible primitive $^{7}$ or analyze it in terms of a non-modal notion of essence ${ }^{8}$ or grounding ${ }^{9}$. In what follows, I will collectively refer to these as heavyweight approaches.

Since heavyweight views presuppose controversial pieces of ideology, conservative alternatives are of considerable interest. ${ }^{10}$ For one, notions like necessity and parthood are often considered well understood and independently needed. For another, while ontological dependence requires a sui generis epistemology on heavyweight views, conservative accounts allow us to refer back to the epistemology of the analysans notions. ${ }^{11}$

One alternative to the heavyweight orthodoxy is that the very notion of ontological dependence is unintelligible. ${ }^{12}$ I don't find this promising (unintelligibility claims are generally hard to defend). A less radical approach would be to understand ontological dependence in relatively uncontroversial terms we already need for other purposes. This was the ambition of the Modal Analysis, and is also what I will try to

${ }^{6}$ See also Correia (2005: 39-46)

7 Thomasson (1999: Ch. 2), Potter (2004: 39-40), and Barnes (2012: 879)

${ }^{8}$ Fine (1995: 273); cf. Fine (1994), Koslicki (2012)

${ }^{9}$ Correia (2005: 66)

${ }^{10} \mathrm{My}$ own view, which I won't defend here, is that the notion of grounding is explanatorily redundant Kovacs 2017), and that pace Fine, essence is amenable to a straightforward modal analysis. On the latter count, I'm influenced by Cowling 2013; see also Wildman 2013.

${ }^{11}$ Cf. Hofweber (2009: 273-4)

${ }^{12}$ Daly 2012: (99-100); cf. Hofweber (2009) 
do. I will defend Dependence Deflationism, the view that ontological dependence can be explained in modal and broadly constructive terms (I will later explain what the latter means). I will argue that while these concepts cannot give us a reductive analysis of ontological dependence, in an important sense they can make the notion fully intelligible. I won't try to persuade committed heavyweight theorists to prefer this view to their own, but I hope to convince them that the theory deserves their attention.

The rest of the paper will go as follows. Section 2 will explain the notion of an aggregative cluster concept, a concept that can be understood, but not fully analyzed, in terms of the various relations it "aggregates". Section 3 will propose the hypothesis that ontological dependence is an aggregative cluster of modal and constructive relations. In section 4, I will test this hypothesis against several examples and argue that it can account not only for clear cases of ontological dependence but also for the source of disagreement in controversial ones. In section 5, I will offer two supplementary arguments for my view, one revolving around the epistemology of ontological dependence and another based on the relation's formal properties.

Before proceeding, I should make explicit two methodological assumptions. First: some philosophers ("pluralists”) distinguish various kinds of ontological dependence: rigid and generic, de re and de dicto, existential and essential, etc. ${ }^{13}$ Others ("generalists") simply talk about ontological dependence and don't make these

13 Lowe (1994), Thomasson (1999: Ch. 2), Correia (2005, 2008), Schnieder (2006), Koslicki (2012, 2013), and Tahko and Lowe (2015) 
distinctions. ${ }^{14}$ Though I have something to say about the specific types, I will mostly focus on the general notion, for two reasons. First, though the generalist conception will be my starting point, ultimately I won't rely on it: as I will show in section 3, Deflationism can also account for various species of ontological dependence. Second, I will argue in section 5.2 that the main motivation for pluralism stems from problems with generalism my view can handle at least as well.

Second: I aim to provide an account that can accommodate a wide range of views about what depends on what, but the theory is not intended as a neutral arbiter consistent with any first-order position. ${ }^{15}$ For example, since I reject non-modal notions of essence, one would search in vain for a discussion of essential dependence in this paper. When speaking of ontological dependence, I'm interested in a concept that strikes a good balance between fitting our intuitions and certain theoretical desiderata. Such desiderata include conceptual links to other metaphysical notions, flexibility about the relation's formal properties, and a simple epistemology. While I think the deflationary view does well on these counts, it might end up capturing something that doesn't completely coincide with the standing notion of ontological dependence. In that case, you should read this paper in a revisionary spirit: we should use 'ontological dependence' to express the concept I will describe, since the theoretical benefits are worth it.

\section{Aggregative cluster concepts}

\footnotetext{
${ }^{14}$ Cameron (2008), Schaffer (2009), Paseau (2010), Jenkins (2011), and Barnes (2012, forthcoming)

15 Thus my approach is closer to Peramatzis's (2011) than to Correia’s (2005: 9-11).
} 
An important class of concepts - aggregative clusters, as I shall call them - can be understood as "weighted totals" of certain relations, in terms of which they nonetheless cannot be analyzed. Consider is bigger than. Whether some $x$ is bigger than some $y$ is a function of various factors having to do with comparative size. Simplifying somewhat, let's say it's a function of the pattern in which they instantiate is taller than, is wider than, is longer than, and is heavier than. Call these relative bigness factors. When $x$ and $y$ instantiate a relative bigness factor, this speaks in favour of (but doesn't entail) $x$ being all things considered bigger than $y$. Call the set of principles telling us how the relative bigness factors between any $x$ and $y$ weigh against each other the rules of aggregation. Of course, the concept shows a certain amount of indeterminacy, as there is no fully specific set of rules governing it. But some cases are obvious: for instance, if $x$ is longer, taller, wider and heavier than $y$, it's also bigger.

This preliminary characterisation needs some adjustments. First, to figure out whether some $x$ is bigger than some $y$ it's not enough to know whether $x$ is taller, heavier, longer, or wider than $y$. It also matters how much taller, heavier, longer or wider $x$ is. I take it that this is an accidental feature of is bigger than, not an essential feature of aggregative clusters, and results from the fact that most of the properties we are in the habit of referring to are gradable. In what follows, I will ignore the gradability of the relative bigness factors, since this feature of the example is irrelevant to my present purposes (however, see footnote 26).

Second, whether is bigger than applies on an occasion is sensitive to whether the putative relata instantiate relations along sufficiently many dimensions. These relations don't necessarily have to be relative bigness factors; they could also be 
symmetric relations in the vicinity, for example being as long as or being as heavy as. If there are too many dimensions along which two entities instantiate no comparative size relation (too many unsaturated dimensions), they won't stand in any all-in relative bigness relation. For example, no ordinary object stands in any such relation with the empty set, since they don't instantiate relative bigness factors along any dimension. More controversially, compare a $1.25 \times 1.25$ feet two-dimensional surface with an ordinary bowling ball. I would say that the surface and the ball bear no comparative all-in size relation to each other because there are too many unsaturated relative bigness dimensions between them.

Bearing these qualifications in mind, we can say that is bigger than is an aggregative cluster that applies to some $x$ and $y$ just in case taking into consideration their weight, height, length, width, $x$ is all things considered bigger than $y$. It's reasonably clear why these factors yield a notion of all-in comparative size: to be heavier is to be bigger with respect to weight, to be longer is to be bigger with respect to length (etc.), and to be bigger simpliciter is to be bigger all things considered. ${ }^{16}$ But why is it that it's these factors, rather than some others, that yield an all-things-considered notion of relative bigness? After all, weight and extension are

\footnotetext{
16 An anonymous referee reports different intuitions about a cognate notion I used in an earlier version, is larger than, and thinks that to be larger than something is simply to have greater volume. I find 'is bigger than' harder to hear so as to only track relative differences in volume; to those who disagree, the best I can offer are counterexamples. Here's one: when sensing danger, various species of animals inflate themselves. We colloquially say that when they do so, they look bigger, which strongly implicates that they don't actually get bigger. But they would if 'is bigger than' simply meant having greater volume.
} 
very different kinds of dimensions, so we shouldn't expect them to yield a particularly unified relation. The answer is that, so far as I can see, this is how the concept works in ordinary discourse. Our judgments of relative bigness are indeed a mishmash of judgments about such disparate relations; as a result, the concept is rarely used in theoretical contexts but may still serve as a useful heuristic, absent more precise means of comparison.

Since this characterisation of is bigger than leaves the rules of aggregation unspecified, it doesn't amount to a reductive analysis. Still, there is an important link between is bigger than and the relations it aggregates: the former can be explained in terms of the latter, where the force of 'explanation' is conceptual. This is primarily an epistemological thesis: it implies that is bigger than can be made intelligible in terms of the relations it aggregates. Suppose someone describes two animals you have never heard of, A and B. Knowledge of the comparative relations of mass, height, length and width between them would put you in a position to know, within the limitations set by the indeterminacy in the rules of aggregation, whether A is bigger than $\mathrm{B}$. This last qualification is important because there are cases in which even once all the factors are in, you couldn't decide whether A is bigger than B. Importantly, such cases can exist even if you are fully competent with the concept is bigness than. Perhaps if there were further rules guiding our use, you would be able to decide whether $x$ is bigger than $y$. But there aren't, so in certain cases you cannot possibly know whether the concept applies to an ordered pair. ${ }^{17}$

${ }^{17}$ Following an anonymous referee's suggestion, I note that the situation is analogous to the Problem of the Many. Even if being fully competent with the concept chair implies that we know there is only 
Given the large number of ways in which the rules of aggregation for relative bigness could have been specified, it's natural to think about the hard cases in the following way. There are lots of abundant relations in the vicinity of is bigger than. ${ }^{18}$ They aggregate the same factors but differ in how much weight they assign to them: for instance, being bigger than $n_{1}$ treats height as more significant, being bigger than ${ }_{2}$ assigns more importance to weight, etc. Moreover, it's indeterminate which of these relations 'is bigger than' refers to. In borderline cases, the rules of aggregation could be made more precise in ways compatible with either verdict. 'Is bigger than' also plausibly displays a certain amount of context-sensitivity: it expresses different abundant relations in different contexts, each with its own weighing of relative bigness factors. (Note that this is compatible with the claim that the expression picks out an aggregative cluster concept even within each context.)

To demonstrate some features of aggregative clusters, I used the example of is bigger than. Many other notions also carry the mark of aggregative clusters; examples may include beating in a battle, colouring, spicing up, and others. But why worry so much about these concepts? Aggregative clusters provide an interesting case study of how conceptual unanalysability can come apart from theoretical indispensability. ${ }^{19}$ Relative bigness is a case in point: in theoretical contexts, any information conveyed in terms of relative bigness could be conveyed more accurately in terms of the relative bigness factors. This doesn't mean that the concept is completely useless,

one chair where there is a collection of particles arranged chair-wise, we don't thereby know which particular collection composes a given chair.

18 See Lewis (1983) on the distinction between sparse and abundant properties and relations.

${ }^{19}$ See Dorr (2004: 157) for similar remarks on predicates that are unanalysable because they are vague. 
since overall bigness comparisons convey some information, and in certain practical settings we care about convenience more than about accuracy. But in theoretical contexts, questions about what is bigger than what tend to be less interesting than specific questions about comparative size along some particular dimension.

\section{Ontological dependence as an aggregative cluster}

Above I characterised aggregative clusters through the example of is bigger than. I now propose the hypothesis that ontological dependence, too, is an aggregative cluster concept of modal and constructive relations, as listed below:

1) Necessarily, if $y$ exists then $x$ exists (in short: $y$ rigidly necessitates $x$ ), but not vice versa

2) $\mathrm{F} x$ and necessarily, if $y$ exists then there is a $z$ such that $\mathrm{F}_{z}$ (in short: $y$ generically necessitates $x$ ), but not vice versa 3) $x$ is a constituent of $y$, but not vice versa

Clauses 1)-3) comprise what I mean by "modal relation". My use of "constructive relation" and "constituent", however, requires more explanation.

As a first approximation, take the view that parthood and composition are category-neutral relations. On a radical version of this view, the composition relation obtains not only between material objects and their proper parts, but also between objects and their properties (for example, on a bundle theory of objects), structured 
facts and their constituent individuals and properties, and even sets and their ancestral members. ${ }^{20}$

While I'm sympathetic to this radically category-neutral conception of composition, I won't presuppose it. So I will use the word 'constructive relation' as a general expression for relations that that hold between various types of compound entities and their constituents: material composition, ancestral set membership, property-bundling, the relation between facts and their individuals and properties, and perhaps more. Thus, while a category neutralist can simply say that 3) covers asymmetric parthood, category restrictionists can replace this with reference to whichever relations category neutralists lump under parthood (restrictionists will differ on what these exactly are). The choice between category-neutral and restricted views makes no difference to the forthcoming account of ontological dependence. Nor does the frequency with which constructive relations are instantiated, though of course this does have a bearing on the extent of ontological dependence (e.g., ontological dependence is never instantiated between composite material objects and their parts if the former don't exist).

I think there is an intimate conceptual connection between the relations listed under 1)-3) and ontological dependence. A view in the vicinity of mine Deflationary Pluralism, as I will call it - would contend that 1)-3) are a species of ontological dependence. According to the view I favour, they are species of another

\footnotetext{
${ }^{20}$ See Fine (2010) for the view that ancestral set membership is a kind of parthood; see also Simons (1987), Armstrong (1997), McDaniel (2001), and Paul (2002) for other neutralist views. Most category neutralists accept compositional pluralism, the (logically independent) view that parthood comes in various kinds.
} 
(non-ontological) kind of dependence, which licenses ontological dependence claims in a more indirect way. I will first present my own view and return to Deflationary Pluralism in section 5.

The relations listed under 1)-3) plausibly track some kind of dependence, even if not full-blown ontological dependence. Each of the following claims has some attraction:

(a) If the existence of $y$ rigidly necessitates the existence of $x$, but not vice versa, then $y$ rigidly modally depends on $x$

(b) If the existence of $y$ generically necessitates the existence of $x$, but not vice versa, then $y$ generically modally depends on $x$ (c) If $x$ is a constituent of $y$, but not vice versa, then $y$ constructively depends on $y$.

As I understand (a)-(c), they state not controversial theses about ontological dependence but rather obvious truisms about other notions of dependence. This is because they track a sort of hierarchical structure in which the entities higher up presuppose and require, in some metaphysical sense, the entities lower down, and such structures by themselves license 'dependence'-talk.

Take asymmetric rigid and generic asymmetrical necessitation. Before encountering Fine's counterexamples, these were frequently identified with species of ontological dependence. If we want to avoid symmetric dependence, the most natural view in the modal account's vicinity would replace them with their asymmetric versions (Correia 2005: 35). Moreover, even opponents of the Modal Analysis take 
seriously the idea that the analysis captures some notion of dependence, if not the metaphysically significant notion contemporary metaphysicians are interested in. ${ }^{21}$ My point can be buttressed by considering some locutions frequently used to express dependence: when A depends on B, A's existence requires and presupposes the existence of B (or something of B's kind); for A to exist, B (or something of its kind) needs to exist; and so on. Fine's counterexamples taught us not to understand these locutions modally; they nonetheless clearly have a purely modal reading.

It's harder to argue with full generality that constructive relations convey a sense of dependence, since to convince some category restrictionists I would need to go through the entire (possibly open-ended) list of constructive relations they distinguish from parthood. Instead, I will argue that both asymmetric parthood (between material objects) and a relation all category restrictionists distinguish from parthood, ancestral set membership, induce a kind of dependence.

Most philosophers think that wholes ontologically depend on their proper parts $^{22}$, while Schaffer (2010) argues for priority monism, the view that every material object ontologically depends on the cosmos. I will discuss this view in section 4; for now, I will confine myself to a brief remark. Even if priority monism were true, it would remain correct to say that wholes depend on their parts mereologically. In a purely mereological sense, proper parts are always prior to the wholes they compose; the question is whether priority and dependence in this sense coincide with the

21 See, for instance, Correia (2008: 1023), Hoeltje (2013), and Tahko and Lowe (2015: §1); cf. Peramatzis (2011: 234-5) on a modal notion of dependence in Aristotle.

22 See Kim (1994: 67), Conee and Sider (2005: 68), Markosian (2005: §3), Cameron (2014), and Skiles (2015). 
relation of ontological dependence most metaphysicians are interested in. ${ }^{23}$ If Schaffer is correct, then an object's parts can ontologically depend on the object they compose, yet this wouldn't prevent the whole from also mereologically depending on the parts.

Similar remarks apply to ancestral set membership. In the cumulative hierarchy, sets "come after" and "presuppose" their ancestral members. This is a kind of dependence, even if not the kind Fine posits between Socrates and his singleton set. According to Incurvati's minimalist view, for instance, there is nothing more to the iterative conception of a set than the narrative convention that introduces sets as occurring at various levels of the cumulative hierarchy (2012: 82). Incurvati emphasizes that this doesn't imply that sets ontologically depend on their members. I agree. But to my mind, the convention does suffice for sets to depend on their members in some sense, even if not the ontological sense. For this reason, we can say that sets depend on their members at least in a purely set-theoretic sense.

As I said, (1)-(3) are notions of some kind of dependence, albeit not ontological dependence. This is important to emphasize because it also clarifies the sense in which my account is reductive and the sense in which it isn't. If (a)-(c) are correct, explaining ontological dependence in terms of 1)-3) can be successful only because we already have some understanding of dependence simpliciter. So, we are explaining ontological dependence in terms of other kinds of dependence, rather than concepts that have nothing to do with dependence. This feature is unobjectionable, and is one my account shares with the Modal Analysis. The Modal Analysis was once

\footnotetext{
${ }^{23}$ See Hall's (2010: Supplement) remarks on the "mereological hierarchy"; cf. Paul (2012: 221-2).
} 
considered plausible precisely because rigid necessitation is an implicitly dependenceinducing concept. Fine's great insight was that this dependence was not of the ontological sort we have been looking for (Fine himself would probably disagree with this assessment). ${ }^{24}$

What about the plethora of "dependence relations" frequently discussed in metaphysics as well as in the philosophy of mind, such as micro-based determination, functional realisation, or the determinable-determinate relation? Shouldn't they also be treated as implying at least some non-ontological kind of dependence and added to our list of 1)-3)? No. Recall that by 'ontological dependence' I mean the (family of) relation(s) targeted in the specialized literature. This differs from the various determination relations often misleadingly branded as "dependence relations". That said, one might want to be more liberal about what counts as a dependence factor and still accept a view in the spirit of Deflationism. I think such liberal approaches are likely based on conflating dependence and determination, but won't argue the point here. Suffice it so say that $I$ will proceed with the meagre list of factors I drew above.

Two further clarifications before I give the official statement of my view, both familiar from section 2. First, although ontological dependence aggregates modal and constructive relations, I cannot say exactly how it aggregates them - the rules of aggregation are somewhat indeterminate. Second, whether ontological dependence applies

\footnotetext{
${ }^{24}$ My point is analogous to one Cameron (2012) made about analysing modality: instead of worrying about whether a purported analysis is "implicitly modal", we should focus on whether the concepts in its analysans are concepts in good standing that we need anyway. Mutatis mutandis for accounts of ontological dependence (thanks to an anonymous referee for forcing me to be clearer here).
} 
to some $x$ and some $y$ is sensitive to whether the putative relata instantiate relations along sufficiently many "dependence dimensions". Similarly to the case of is bigger than, symmetric relations in the vicinity of (1)-(3) can saturate a dependence dimension between $x$ and $y$. For example, improper parthood and symmetric rigid or generic necessitation don't contribute to either of $x$ or $y$ ontologically depending on the other, but might help establish enough of a connection between them so that another relation that qualifies as a dependence factor could tilt the direction either way. This phenomenon also helps us understand why Socrates doesn't ontologically depend on the number five: although each dependence factor between them speaks in favour of Socrates depending on the number five, no non-modal dependence dimension between them is saturated. Hence, there isn't enough of a connection between the two for the modal factors to establish ontological dependence. (In this regard, the situation is similar to the case of the two-dimensional surface and the ball from section 2. $)^{25}$

Now we are in a position to state the deflationary position. Ontological dependence is an aggregative cluster concept: a concept that applies to some $x$ and $y$ just in case taken into consideration all the dependence factors, $x$ depends on $y$. How so? Each

25 Should we say that ontological dependence always requires the presence of some constructive dependence factor? I'm undecided: I'm reluctant to build such a strong claim into the official theory, but it's hard to think of counterexamples. An anonymous referee suggests that physicalists might say that a phenomenal experience depends on a brain state without the two instantiating any constructive relation. I'm not convinced; I think the proper physicalist doctrine is that phenomenal states are determined by brain states, not that they depend on them. This is especially plausible on non-reductive views, which allow for multiple realisability. 
of 1)-3) by itself implies some kind of dependence, and we can aggregate these to get an all-things-considered notion. So, just like with other aggregative clusters, the relation between ontological dependence and the dependence factors is conceptual explanation. This implies that complete knowledge of the pattern of modal and constructive relations by $x$ and $y$ would put you in a position to know, within the constraints posed by the indeterminacy in the rules of aggregation, whether $x$ ontologically depends on $y \cdot{ }^{26}$

By now it should also be clear what makes this view deflationary. My dependence factors don't form a very unified class; analogously to 'is bigger than', judgments of ontological dependence turn out to be a mishmash of judgments about modal and constructive relations. Moreover, since we could have specified the rules of aggregation in a number of ways, the aggregate notion displays some indeterminacy. But then, any question of the form "Does $x$ ontologically depend on y?" ultimately boils down to two sub-questions. First, which dependence factors are instantiated in the case at hand? This question is metaphysical, but it can be addressed without any mention of ontological dependence itself; all we need to focus

${ }^{26}$ In section 2, I put to the side the complication that relative bigness admits of degrees. It's worth pointing out that the disanalogy with ontological dependence is less clear-cut here than appears at first glance, since one might want to allow for indeterminate parthood, fuzzy set membership, and even indeterminately true modal claims. This would lead to a notion of ontological dependence that admits of degrees. Koslicki (2015: 127) has recently argued that the (historically related) notion of substance admits of degrees, and also attributed that view to Aristotle. Unfortunately, I lack space to explore this issue in further detail here; in the main text, I will keep focusing on the all-or-nothing notions of ontological dependence and the dependence factors. 
on are the patterns of modal and constructive relations instantiated by the putative relata. Second, what do the rules of aggregation say about how these relations should be weighed against each other? This question is semantic/conceptual, and no deeper than the analogous question about is bigger than. In light of these considerations, we can say that the account of ontological dependence I'm offering is deflationary or "lightweight". 27

The general characterisation of Deflationism ends here. This is a good place to say a few words about the specific types of ontological dependence pluralists often distinguish in the literature. Barnes (forthcoming) has recently argued that these distinctions are arbitrary and best seen as attempts to explain away counterexamples to the asymmetry of ontological dependence. I agree that the standard distinctions are rather arbitrary, and now we can also explain why: they result from singling out a relation within an aggregative cluster and imposing it on the cluster. For example, rigid existential dependence can be defined as follows:

$x$ rigidly depends on $y=_{\text {def }}(1) x$ ontologically depends on $y,(2)$ the existence of $x$ rigidly necessitates the existence of $y$

Thus understood, rigid dependence is on par with is bigger and taller than - an admittedly artificial-looking concept. However, as we will see in Section 5.2, we don't need such distinctions to resist putative counterexamples to asymmetry. Not that we have to

${ }^{27}$ Notice the analogy with modal neo-conventionalism (Cameron 2010, Sider 2011: Ch. 12), according to which there are plenty of different things we could have meant by 'necessary', 'possible', etc., and the way we use these words isn't superior to other, non-actual, uses. 
resist them; Deflationism can accommodate a wide variety of views about the formal properties of ontological dependence. But I'm getting ahead of myself. Let's see first how the theory fares in practice.

\section{Dependence Deflationism at work: some cases}

In this section, I will discuss some putative cases of ontological dependence. My goal is to illustrate that Deflationism fits our intuitive judgments of ontological dependence and can also explain disagreement over controversial cases.

A. Socrates and $\{$ Socrates\}. Intuitively, \{Socrates\} ontologically depends on Socrates, but not vice versa. There is a constructive dependence factor: Socrates is an ancestral member of $\{$ Socrates\}, but not the other way round. Moreover, there is a modal connection that isn't a dependence factor but saturates a dependence dimension (and thus prevents a situation in which there aren't enough saturated dependence dimensions): Socrates and \{Socrates\} rigidly necessitate each other. Finally, no dependence factor favours the dependence of Socrates on $\{$ Socrates\}. So, we have a good case for thinking that $\{$ Socrates\} ontologically depends on Socrates.

This is one of the most uncontroversial cases of ontological dependence: the few who deny that Socrates ontologically depends on \{Socrates\} do so due to their general scepticism about the notion (e.g. Incurvati 2012). I think this is no coincidence: the ontological dependence of $\{$ Socrates\} on Socrates is uncontroversial because the dependence factors they instantiate are uncontroversial and unambiguously point in the direction of \{Socrates\} depending on Socrates.

B. Priority monism vs. priority pluralism. A more controversial case is the ontological dependence of material wholes on their parts. To simplify things a bit, I 
will focus on two restricted theses that are relatively easy to contrast: the view that the cosmos ontologically depends on its simple parts (call it pluratomism), and the view that every simple ontologically depends on the cosmos (call it monatomism). ${ }^{28}$

Which dependence factors speak in favour of which thesis? Most obviously, there is a constructive dependence factor that speaks in favour of pluratomism: the cosmos is composed of the simples. What about the modal dependence factors? That hangs on whether there are "gunky" worlds that contain infinitely divisible objects (gunk) and "junky" worlds with no maximal mereological sum to qualify as the cosmos. If there are no gunky worlds, the cosmos generically necessitates the simples. And if there are no junky worlds, the simples generically necessitate the existence the cosmos. If generic necessitation goes only in the first direction, that's a dependence factor in favour of pluratomism; if only in the second direction, that's a dependence factor in favour of monatomism; and if it goes both ways, that saturates a dependence dimension without tilting the direction of dependence either way.

Thus we get the best distribution of dependence factors for pluratomism if there are junky but no gunky worlds, and for monatomism if there are gunky but no junky worlds. In the latter case, we have only one dependence factor (composition) supporting the dependence of the cosmos on its simple parts, and another one supporting the dependence of the simple parts on the cosmos.

Now, Schaffer (2010: 61-5) offers an argument for priority monism, the view that every proper part of the cosmos depends ontologically on the cosmos, based on the

28 I will assume that there are simples and that mereological essentialism is false. Relaxing these assumptions would make the discussion more complicated in tangential ways. 
possibility of gunk and the impossibility of junk. ${ }^{29}$ So, the above result shouldn't be too surprising, although it ought to be qualified in two ways. First, Schaffer's gives several other arguments for priority monism, which rely on substantive links between fundamentality and other metaphysical relations, for example emergence (2010: 5557). My deflationary framework cannot make sense of these arguments, but I don't think it should, either. Schaffer doesn't recognize my distinction between grounding and ontological dependence, and uses 'grounding' and 'dependence'-talk more or less interchangeably. As a result, he conflates two distinct theses: (1) that the proper parts of the cosmos ontologically depend on the cosmos, and that (2) (facts about) the proper parts of the cosmos are grounded in (facts about) the cosmos. The argument from gunk is naturally construed as supporting the first thesis, whereas Schaffer's other arguments concern grounding/determination, rather than ontological dependence strictly understood.

While Dependence Deflationary confirms that whether gunk, but not junk, is possible is relevant to the debate, it doesn't imply that such a combination would settle the debate in Schaffer's favour - rather, it would leave us with one dependence factor supporting monatomism and another one speaking against it. I consider this the right result. For even if Schaffer turned out to be right about the relevant modal and mereological facts, pluratomism wouldn't stop seeming somewhat plausible. The previous section suggests an explanation of why this is so. There are many abundant relations that could have been meant by 'ontological dependence'. If Schaffer is right about the direction of ontological dependence, this is because the rules of

\footnotetext{
${ }^{29}$ Bohn (2009) objects to the argument on the basis that if gunk is possible, so is junk.
} 
aggregation happen to assign more weight to generic necessitation than to asymmetric parthood (of course, Schaffer himself would disagree with this diagnosis).

I don't know whether this is the case; through the lens of Deflationism, it doesn't really matter. For the deflationist, once all the modal and constructive facts are settled, asking what depends ontologically on what is like investing a lot of time and money in comparing the mass, diameter and volume of two planets and, once all the data are in, pressing the question: "Okay, but which one is bigger?"

C. Tropes and their bearers. Tropes are often thought to ontologically depend on their bearers, but only by those who believe that tropes are non-transferable: necessarily, if a trope exists then so does its bearer, whereas the bearer could exist without most of its tropes. ${ }^{30}$ Matters are less straightforward in the case of necessary tropes. Some, like Simons (1994), argue that trope-bearers and their necessary tropes mutually ontologically depend on each other. I reject this possibility (though see section 5.2), but I'm sympathetic to the idea that the rigid necessitation of a necessary trope by its bearer weakens the case for its ontological dependence on that bearer.

The importance of modal connections becomes even more evident when we focus on views that deny the non-transferability thesis. These come in many flavours $^{31}$; what matters is that their advocates tend to think of tropes as the most

\footnotetext{
30 Mulligan, Simons and Smith (1984: 290-1), Simons (1987: 304), Correia (2008: 1015-6), Koslicki (2012: 201), Tahko and Lowe (2015: §6.3)

${ }^{31}$ See Williams (1953), Campbell (1981, 1990), Schaffer (2003), and Cameron (2006), among others.
} 
basic kinds of things ${ }^{32}$, and of material objects as bundles of tropes. I cannot get into further details here; suffice it to say that if objects are bundles of tropes, this creates some pressure to say that they ontologically depend on these tropes. I'm not alone in with this verdict: Koslicki (2012: 189, f4), too, notes that bundle theorists with reductive ambitions should claim that it's the bearers that ontologically dependent on their tropes, rather than the other way round.

In conclusion, we can say that the claim that (at least contingent) tropes ontologically depend on their bearers seems the least plausible if tropes are both transferable and constituents of the objects they are tropes of, and the most plausible if neither is the case. This meshes not only with Deflationism, but also with the thinking of actual trope theorists.

D. Facts and their constituents. Structured propositions, facts and events are often thought to ontologically depend on their constituents. ${ }^{33}$ For simplicity's sake I will focus on facts, but much of what I have to say also applies to other structured compounds. Take the fact that John loves Mary - in usual notation: John loves Mary]. This fact has as constituents John, the relation of loving, and Mary. Why think it ontologically depends on them? For one, the fact is constructed out of these things (perhaps by having them as parts, perhaps by a sui generis fact-constituency relation). For another, the fact has these constituents necessarily: [John loves Mary] cannot exist unless John, Mary and the loving relation do (the reverse isn't true: John, Mary and loving could exist without [John loves Mary] existing). So both a constructive and

\footnotetext{
32 Williams (1953), Campbell (1990)

33 See Fine (1995), Thomasson (1999: 26), Correia (2008: 115), Koslicki (2012), among others.
} 
a modal dependence factor speak in favour of facts ontologically depending on their constituents. (As Fine points out, there is two-way necessitation in the case of existential facts: [Socrates exists] exists iff Socrates does (1995: 271). Likewise for facts involving individuals and their necessary properties. I'm happy to concede these points, since (1) the constructive dependence factor still holds, which - along with a saturated modal dimension - might be enough to secure the facts-on-constituents direction, and (2) it does strike me as somewhat less obvious that such facts ontologically depend on their constituents than that ordinary ones do.)

Not everyone accepts this view. Armstrong (1997) also believes in structured facts, but he often seems to take them to be basic things. How can we reconcile this with Armstrong's "Tractarian" ambitions? Barnes (forthcoming) has recently suggested that we interpret Armstrong as defending the view that facts and their constituents ontologically depend on each other. Instead I would argue that Armstrong has been misled by his doctrine of ontological free lunch, according to which supervenient entities are "no addition of being". More precisely, (1) he thinks that supervenience is sufficient for (something in the vicinity of) ontological dependence, but (2) uses a mistaken definition of supervenience, which (3) leads to an implausible view about ontological dependence. Armstrong uses the following definition of supervenience:

'[E]ntity Q supervenes upon entity $\mathrm{P}$ if and only if it is impossible that $\mathrm{P}$ should exist and Q not exist, where P is possible' (1997: 11) 
As Bricker (2006: 267-8) notes, this definition is fairly non-standard. Supervenience is usually understood as a covariance relation, but Armstrong's definition is neither necessary nor sufficient for any interesting kind of covariance.

In fact, Armstrong's definition identifies supervenience with the right-hand side of the Modal Analysis, supplemented with an extra possibility condition. This is remarkable because it means that whenever the Modal Analysis predicts that A depends on B, Armstrong's view will predict that B depends on A. It shouldn't be surprising, then, that his verdict about facts and their constituents also runs counter to orthodoxy: this is to be expected when something close to the once-standard definition of ontological dependence is used to define the converse of the same relation! For this reason, I think that given his other views Armstrong was simply wrong to think that a fact's constituents depended on that fact. ${ }^{34}$

However, this doesn't mean that "facts first" views can't be defended. One could do so by denying that facts are structured in the first place. This is exactly the view of Turner (2016: Ch. 1), who has recently tried to place a broadly Tractarian approach on firmer footing. While Turner doesn't quite say that individuals and properties ontologically depend on facts in my narrow sense of 'ontological dependence' (he doesn't even officially commit himself to individuals and properties), he clearly denies that the dependence holds in the other direction. From a deflationary perspective, he has grounds for doing so: once we deny that facts are structured, the only remaining dependence factor speaking in favour of the dependence of facts on objects and properties will be asymmetric rigid necessitation.

\footnotetext{
${ }^{34}$ See Ellis (2001: 65) for a similar criticism.
} 
And at that point the deflationist can insist, with some plausibility, that there are too many unsaturated dependence dimensions for such dependence to obtain.

This closes my discussion of particular cases. I obviously couldn't give a complete overview, and some readers will inevitably feel that they had problem cases I haven't discussed. For now, we can at least conclude that Deflationism does a good job explaining why widely cited cases of ontological dependence are plausible, and why others are more controversial.

\section{Two arguments for Deflationism}

Above I argued that Deflationism explained some widely cited, as well as some more

controversial, cases of ontological dependence. I will now build on this conclusion to give two positive arguments for Deflationism.

\subsection{The epistemic argument}

In the various first-order debates, modal and constructive relations are widely regarded as evidentially relevant to the direction of ontological dependence. Yet few think that the presence of any of these relations by itself settles what depends ontologically on what. Deflationism explains this practice: the dependence factors constitute evidence in favour of dependence claims because ontological dependence aggregates them; yet none of these relations settles the presence and direction of ontological dependence, since ontological dependence doesn't require any particular 
relation in the cluster. So, we have reason to think that Deflationism is true. Call this the epistemic argument. ${ }^{35}$

Now, I'm not claiming that Deflationism is the only way to make sense of the evidential role of the relations I consider dependence factors. But it provides an especially simple explanation and uses less controversial resources than rival views. For example, Fine understands both necessity (1994) and ontological dependence (1995) in terms of essence. While this view might explain the evidential relevance of necessitation to ontological dependence, it does so at the cost of relying on a controversial non-modal notion of essence. Moreover, it does little to explain the evidential relevance of constructive relations.

The epistemic argument also highlights an advantage of my view over Deflationary Pluralism, which treats the dependence factors are species of ontological dependence. Deflationary Pluralism explains why certain relations are evidentially relevant to ontological dependence but yields a radically revisionary view about their evidential weight. Few think, for instance, that the mereological facts alone settle whether wholes ontologically depend on their proper parts (otherwise we couldn't make sense of the debate over priority monism). My view, by contrast, implies only that if $x$ is a part of $y$ but not vice versa, this counts in favour of $y$ ontologically

35 Bennett (2017: 141-3) gives a similar argument against primitivism about relative fundamentality in the context of building relations. Like many others, Bennett draws no sharp distinction between dependence and determination, and her notion of building is meant to have some features of both. Wilson (2014) defends a similar view about grounding as a disjunction of "small-g" grounding relations; she too uses 'grounding' and 'dependence'-talk interchangeably. 
depending on $x$, but other factors might ultimately render the dependence claim false. If priority monism is true, this is exactly the case with the cosmos and its parts.

\subsection{The argument from formal properties}

In this section, I will demonstrate two further advantages of Dependence Deflationism. First, it can stay neutral on the formal properties of ontological dependence. Second, it can explain why philosophers often disagree about these formal properties.

Ontological dependence is widely thought to be asymmetric: for any $x$ and $y$, if $x$ ontologically depends on $y$ then $y$ doesn't ontologically depend on $x \cdot{ }^{36}$ But in some conceivable cases $x$ bears $\mathrm{R}$ to $y, y$ bears $\mathrm{R}^{\prime}$ to $x$, and both $\mathrm{R}$ and R' are dependence factors. A deflationary pluralist who takes the dependence factors to be species of ontological dependence cannot avoid concluding, then, that $x$ and $y$ ontologically depend on each other. For example, perhaps the cosmos is composed by some atoms, which rigidly necessitate the cosmos. ${ }^{37}$ Or perhaps properties conceived as Aristotelian universals generically necessitate their instances (they cannot exist uninstantiated), but the instances rigidly necessitate at least their essential properties. ${ }^{38}$

\footnotetext{
${ }^{36}$ See Lowe (1994), Cameron (2008), and Koslicki (2013), among others.

${ }^{37}$ Bennett (2017: 26-9) raises a similar worry about the general notion of building. See also her discussion of why it's not a promising strategy to insist that only one species of building can hold between any two relata; the same considerations apply to ontological dependence.

${ }^{38}$ Lowe (1994)
} 
One answer to these worries is that ontological dependence simpliciter is a very general relation, so it's not that bad if it fails to be asymmetric. What matters is that each species of ontological dependence is asymmetric, and with sufficiently finegrained distinctions, we can ensure that no two things bear the same species of ontological dependence to each other (e.g., the standard answer in the second case is to say that Aristotelian universals generically depend on their instances, which in turn rigidly depend on their essential properties). ${ }^{39}$

I don't see how this response addresses the main worry. Compare is bigger than. George the Great Dane is taller, but narrower, then Mike the Mastiff; yet they aren't bigger than each other. If someone thought they were, it wouldn't help to emphasize that the specific comparative size relations they bear to each other are asymmetric; this wouldn't by itself make the intuition that is bigger than is also asymmetric go away. The same goes for ontological dependence. If we started out with an asymmetry intuition about a particular case, it's unclear why this intuition should go away just because ontological dependence is a general relation comprising more fine-grained asymmetric species.

Deflationism can reconcile the possibility of opposing dependence factors with the asymmetry of ontological dependence. Let me immediately add that we don't need to assume that ontological dependence is asymmetric. So far I have been assuming that it is, but Deflationism also allows us to make sense of revisionary views. Roughly, we can distinguish three positions in the extant literature: (a) ontological dependence is asymmetric, (b) it isn't asymmetric, and not even antisymmetric: some

\footnotetext{
${ }^{39}$ See Lowe (1994: 38-40), Fine (1995: 286), and Correia (2005: 45, f11); cf. Bennett (2017: 27-8).
} 
things ontologically depend on each other; and finally, (c) ontological dependence is antisymmetric but reflexive: everything trivially depends on itself. All along I have been assuming (a), but this choice wasn't mandatory.

Deflationism can accommodate (b)-type views, since nothing in the notion of an aggregative cluster requires such concepts to be asymmetric. Is bigger than is asymmetric, but is at least as big as isn't. If ontological dependence were more like the latter, it could allow for mutual dependence. Better yet, once we recognize that aggregative clusters needn't be asymmetric, we can help ourselves to a conciliatory resolution of the dispute between (a) and (b)-type views. 'Ontological dependence' displays a certain amount of indeterminacy: there are several abundant relations that could have been meant by it, some of which allow for symmetric aggregation while others rule it out. Perhaps the linguistic conventions favour one candidate over the other. Even so, the rival party's mistake is fairly superficial, and they are free to just stipulate a notion of ontological dependence with the desired formal properties. This resolution dovetails nicely with many putative examples of symmetric dependence, which usually cite opposing dependence factors. ${ }^{40,41}$

40 This is the case, I believe, with many of Barnes's (forthcoming) putative examples of symmetric dependence, though I lack space to go over them in any detail here.

41 One might worry that no notion of ontological dependence is asymmetric. Take a (simplified) toy model according to which the dependence factors are $R_{1}, R_{2}$ and $R_{3}$, and something ontologically depends on another thing if the former bears a majority of dependence factors to the latter. Then we can construct a case in which $x$ bears $\mathrm{R}_{1}$ and $\mathrm{R}_{2}$ to $y, y$ bears $\mathrm{R}_{1}$ and $\mathrm{R}_{3}$ to $z$, and $₹$ bears $\mathrm{R}_{2}$ and $\mathrm{R}_{3}$ to $x$. The rules of aggregation and the transitivity of ontological dependence imply a violation of asymmetry (as well as irreflexivity). I think this objection does show something significant: the rules of 
What about (c)-type views? I stipulated that each dependence factor was asymmetric, but we can cook up a concept - ontological dependence*, say - that aggregates non-symmetric modal and constructive relations, for example proper-orimproper parthood and (non-symmetric) rigid and generic necessitation. Presumably, everything bears to itself a significant subset of these "dependence* factors", so it's plausible that everything ontologically depends* on itself. The debate between (a)and (b)-type views can thus be understood as one about whether 'ontological dependence' means ontological dependence or ontological dependence*. Although this diagnosis implies that the participants themselves misconceive the nature of their debate (they think they are talking about the same relation, but they aren't), I find it attractive. $^{42}$ While most philosophers assume that ontological dependence is irreflexive and asymmetric, others write as if it was obvious that everything depended

aggregation won't by themselves ensure the asymmetry of an aggregative cluster concept. However, that doesn't mean that we cannot rule out such loops on an independent basis. Let's assume (for simplicity's sake) that the three factors are rigid asymmetric necessitation, irreflexive parthood, and ancestral set membership. Suppose $x$ rigidly asymmetrically necessitates $y$ and $y$ is a proper part of $x$, and $y$ rigidly asymmetrically necessitates $z$ and $z$ is an ancestral member of $y$. To complete the loop, z would need to be both a part and an ancestral member of $x$, which seems impossible. While I lack space to go through every logically possible combination of dependence factors, I'm yet to be convinced that we can find one that yields a loop. (Thanks to Mike Raven for raising this concern.)

42 Elsewhere, I defended a similar diagnosis of putative cases of self-grounding as a trivial limiting case, rather than a genuine departure from the orthodox irreflexive conception; see Kovacs forthcoming. 
on itself. ${ }^{43}$ Since everything plausibly ontologically depends* on itself, it's natural to understand them as using 'ontological dependence' for ontological dependence*.

Let me wrap up. There are various notions, guided by different rules of aggregation, which result in different constraints on the formal properties of ontological dependence. Which of these comes closest to the standing notion of ontological dependence is a question I cannot conclusively settle here, but the deflationary framework can explain why any of the extant views could appear reasonable to its proponents.

\section{Concluding remarks}

In this paper, I attempted to spell out Dependence Deflationism in some detail and offered some reasons for taking it seriously. If the deflationary view is correct, we arguably shouldn't structure our inquiries around the notion of ontological dependence, since the questions we formulate in terms of it could be asked and addressed with more precision in modal and constructive terms. If this were right, we would do well to excise 'ontological dependence' from our vocabulary and focus instead on the deeper philosophical questions that all along underlay our inquiries about dependence. $^{44}$

\footnotetext{
43 See Simons (1987: 295), Thomasson (1999: 26), and Tahko and Lowe (2015: §4.2).

44 I'm grateful to Karen Bennett, Matti Eklund, and Ted Sider, who were generous enough to comment on and discuss with me numerous drafts of this paper. For helpful comments and discussion I'm also grateful to Fabrice Correia, Louis deRosset, Ghislain Guigon, James Lee, Kevin Mulligan, Mike Raven, Brad Saad, Nico Silins, Alex Skiles, Dean Zimmerman, anonymous referees, and audiences at the VIII Annual Mark L. Shapiro Graduate Philosophy Conference at Brown
} 
Tel Aviv University, Israel

\section{References}

Armstrong, D.M. (1997) A World of States of Affairs, Cambridge: CUP.

Barnes, E. (2012) 'Emergence and Fundamentality', Mind, 121: 873-901.

Barnes, E. (forthcoming) 'Symmetric Dependence', R. Bliss and G. Priest (eds) Reality and Its Structure, Oxford: OUP

Bennett, K. (2017) Making Things Up. Oxford: OUP

Bliss, R. and Trogdon, K., 'Metaphysical Grounding,' The Stanford Encyclopedia of Philosophy (Winter 2016 Edition), E.N. Zalta (ed.), URL = <https://plato.stanford.edu/archives/win2016/entries/grounding/>

Bohn, E.D. (2009) 'Must there be a top level', Philosophical Quarterly, 59: 193-201.

Cameron, R.P. (2006) 'Tropes, Necessary Connections, and Non-transferability', Dialectica, 60: 99-113.

Cameron, R.P. (2008) 'Turtles all the way down: regress, priority and fundamentality', Philosophical Quarterly, 58: 1-14.

Cameron, R.P. (2010) 'On the Source of Necessity', in B. Hale and A. Hoffman (eds) Modality: Metaphysics, Logic, and Epistemology, 137-51, Oxford: OUP.

Cameron, R.P. (2012) 'Why Lewis's reductive analysis of modality succeeds in its reductive ambitions', Philosophers' Imprint, 12 (8): 1-21.

Cameron, R.P. (2014) 'Parts Generate the Whole, but They Are Not Identical to It', D. Baxter and A. Cotnoir (eds) Composition as Identity, 90-107, Oxford: OUP.

Campbell, K. (1981) 'The Metaphysic of Abstract Particulars', Midwest Studies in Philosophy, 6: 477-88.

Campbell, K. (1990) Abstract Particulars. Oxford: Basil Blackwell.

Conee, E. and T. Sider (2005) Riddles of Existence: A Guided Tour of Metaphysics. Oxford: Clarendon Press.

Correia, F. (2005) Existential Dependence and Cognate Notions. Munich: Philosophia Verlag.

Correia, F. (2008) 'Ontological Dependence’, Philosophy Compass, 3: 1013-32.

University, the 2014 Syracuse Philosophy Graduate Conference at Syracuse University, and at department colloquia at the University of Geneva and the University of Miami. 
Cowling, S. (2013) 'The Modal View of Essence', Canadian Journal of Philosophy, 43: 248-66.

Daly, Chris (2012) 'Scepticism about Grounding', in F. Correia and B. Schnieder (eds) Metaphysical Grounding, 81-100, Cambridge: CUP

Dorr, C. (2004) 'Non-symmetric Relations', Oxford Studies in Metaphysics, 1: 155-92.

Ellis, B. (2001) Scientific Essentialism. Cambridge: CUP.

Fine, K. (1994) 'Essence and Modality', Philosophical Perspectives, 8: 1-16.

Fine, K. (1995) 'Ontological Dependence', Proceedings of the Aristotelian Society, 95: 269-90.

Fine, K. (2010) 'Toward a theory of part', Journal of Philosophy, 107: 559-89.

Hall, N., 'David Lewis's Metaphysics,' The Stanford Encyclopedia of Philosophy (Fall 2012 Edition), E.N. Zalta (ed.), URL = <http://plato.stanford.edu/archives/fall2012/entries/lewis-metaphysics/>

Hoeltje, M. (2013) 'Introduction', in B. Schnieder, B. Hoeltje, and A. Steinberg (eds) Varieties of Dependence, 9-28, Munich: Philosophia Verlag.

Hoffman, J. and G. Rosenkrantz (1994) Substance among other categories. Cambridge: CUP.

Hofweber, T. (2009) 'Ambitious, Yet Modest, Metaphysics', in D. Chalmers, D. Manley, and R. Wasserman (eds) Metametaphysics, 260-89, Oxford: OUP.

Incurvati, L. (2012) 'How to be a minimalist about sets?', Philosophical Studies, 159: 69-87.

Jansson, L. (2017) 'Explanatory Asymmetries, Ground, and Ontological Dependence', Erkenntnis, 82: 17-44.

Jenkins, C.S. (2011) 'Is Metaphysical Dependence Irreflexive?', Monist, 94: 267-76.

Kim, K. (1994) 'Explanatory knowledge and metaphysical dependence', Philosophical Issues, 5: 51-69.

Kim, J. (1998) Mind in a Physical World, Cambridge, MA: MIT Press.

Koslicki, K. (2012) 'Varieties of Ontological Dependence', in Correia and Schnieder, 186-213

Koslicki, K. (2013) 'Ontological Dependence: An Opinionated Survey', in Hoeltje, Schnieder and Steinberg, 31-64

Koslicki, K. (2015) 'The coarse-grainedness of grounding', Oxford Studies in Metaphysics, 306-44.

Kovacs, D. K. (2017) 'Grounding and the Argument from Explanatoriness", Philosophical Studies, 174: 2927-52

Kovacs, D.M. (forthcoming) 'What is wrong with self-grounding?', Erkenntnis 
Lewis, D.K. (1983) 'New work for a theory of universals', Australasian Journal of Philosophy, 61: 343-77.

Lowe, E.J. (1994) 'Ontological Dependency', Philosophical Papers, 23: 31-48.

Lowe, E.J. (1998) The Possibility of Metaphysics, Oxford: Clarendon Press.

Markosian, N. (2005) 'Against Ontological Fundamentalism', Facta Philosophica, 7: 69-83.

McDaniel, K. (2001) 'Tropes and Ordinary Physical Objects', Philosophical Studies, 104: 269-90.

Melnyk, A. (2003) A Physicalist Manifesto: Thoroughly Modern Materialism. Cambridge: CUP.

Moravcsik J.M.E. (1965) 'Strawson and Ontological Priority', in R.J. Butler (ed) Analytic Philosophy, 2nd Series, 106-19, Oxford: Blackwell

Mulligan, K., P. Simons, and B. Smith (1984) 'Truth-makers', Philosophy and Phenomenological Research, 44: 287-321.

Paul, L.A. (2002) 'Logical Parts', Nô̂s, 36: 578-96.

Paul, L.A. (2012) 'Building the world from its fundamental constituents', Philosophical Studies, 158: 221-56.

Paseau, A. (2010) 'Defining Ultimate Ontological Basis and the Fundamental Layer', Philosophical Quarterly, 60: 169-75.

Peramatzis, M. (2011) Priority in Aristotle's Metaphysics. Oxford: OUP.

Potter, M. (2004) Set theory and its philosophy. Oxford: OUP.

Schaffer, J. (2003) 'The Problem of Free Mass: Must Properties Cluster?', Philosophy and Phenomenological Research, 66: 125-38.

Schaffer, J. (2009), “On What Grounds What,' Chalmers, Manley and Wasserman, $347-83$

Schaffer, J. (2010), 'Monism: The priority of the whole', Philosophical Review, 119: 3176.

Schnieder, B. (2006), 'A Certain Kind of Trinity: Dependence, Substance, Explanation', Philosophical Studies, 129: 393-419.

Schnieder, B. (forthcoming), 'Grounding and Dependence', Synthese.

Sider, T. (2011) Writing the Book of the World. Oxford: OUP.

Simons, P. (1982) 'The Formalisation of Husserl's Theory of Parts and Wholes,' in Barry Smith (ed) Parts and Moments: Studies in Logic and Formal Ontology, 113-59, Munich: Philosophia Verlag

Simons, P. (1987) Parts: A Study in Ontology. Oxford: OUP.

Simons, P. (1994) 'Particulars in Particular Clothing: Three Trope Theories of Substance', Philosophy and Phenomenological Research, 54: 553-75. 
Simons, P. (1998), 'Farewell to Substance: A Differentiated Leave-Taking', Ratio, 11: 235-52.

Skiles, A. (2015), ‘Against Grounding Necessitarianism’, Erkenntnis, 80: 717-51.

Tahko, T. and E.J. Lowe, 'Ontological Dependence,' The Stanford Encyclopedia of Philosophy (Spring 2015 Edition), E.N. Zalta (ed.), URL = $<$ http://plato.stanford.edu/archives/spr2015/entries/dependenceontological/>

Thomasson, A.L. (1999) Fiction and Metaphysics. Cambridge: CUP.

Tlumak, J. (1983) 'Cross-Categorical Priority Arguments', Metaphilosophy, 14: 32-9.

Wildman, N. (2013) 'Modality, Sparsity, and Essence', Philosophical Quarterly, 63: 760_ 82.

Williams, D.C. (1953), 'The Elements of Being', Review of Metaphysics, 7: 3-18, 17192.

Wilson, J. (2014) 'No work for a theory of grounding', Inquiry, 57: 1-45. 